\title{
Measures to Curb Drugs Abuse among Primary School Learners in the Hhohho Region of Eswatini
}

\author{
Nomsa E. Nkhoma Racheal Mafumbate \\ University of Eswatini, Department of Educational Foundations and Management, Faculty of Education
}

\begin{abstract}
The study employed the qualitative approach which followed the exploratory research design to explore the measures to to curb drug abuse. The exploratory research allowed the researches to conduct focused group discussion with 20 primary school learners and in-depth interview with nine teachers and one head teacher from one primary school to explore their general attitudes, views, opinions, feelings and understanding of measures to curb drug abuse. Data was presented and analysed using the thematic analysis method. The study was guided by Bronfenbrenner's 1989 Ecological Systems Theory. The following themes to curb drug abuse emerged from the analysis: media campaigns targeting young people; extensive peer education by guidance and counselling and life skills education; involvement of community leaders discouraging learners in dagga farming; stiffer penalties from the justice system.
\end{abstract}

Keywords: drug abuse, primary school, learner, ecological systems theory

DOI: $10.7176 /$ RHSS/9-24-01

Publication date: December $31^{\text {st }} 2019$

\section{Background}

Drug abuse has become a global phenomenon affecting almost every country though the extent and characteristics vary depending on the country in question (Research Report, Ghana, 2013). The United States of America has citizens who are four times likely to use cocaine in their lifetime than the next closest country, New Zealand ( $16 \%$ vs $4 \%$ ). Marijuana use is more widely reported worldwide, and the U.S. also has the highest rate of use at $42.4 \%$ compared to $41.9 \%$ of New Zealand (Warner 2013). Pakistan has an approximately $44 \%$ of students reporting alcohol and/illicit drug use. This problem is a significant concern for Pakistan College and universities (Khatak, lqbal and Ullah, 2012). A study in Brazil noted with concern that drug abuse does not occur from nowhere (Faria, Queiros, Medeiros, Rosso, and Souza) (2015). It is worth noting that easy access to drugs, use of drugs by family and friends, idleness, dropping out of school and vulnerability to drugs are factors contributing to abuse of drugs.

The youth in Nigeria like many other countries of the world are developing addiction to psychoactive substances. In 2012 The National Drug Law Enforcement Agency (NDLEA) collected drugs use and abuse data from schools, record of patients admitted at mental health institutions for drug related problems and interview of persons arrested for drug offences. The results showed that youths constitute the high risk group of drug trafficking and abuse. Friends and schoolmates account for about $90 \%$ of the source of influence of the use and abuse of various psychoactive substances. In Kenya Kavutha (2015) held a study on the influence of drug use on academic performance among secondary school students in Matinyani District. The study established that drug use is common among secondary school students. It further established that drug abuse lead to poor academic performance and increase in indiscipline cases among students. In South Africa Mudavanhu and Schenck (2014) findings showed that the reasons for substance abuse among youths in Grabouw include multiple personal and contextual factors in which the family plays a major role.

In Eswatini a closely related study was held by Mhlongo (2005) and the results showed that these adolescents abuse alcohol to such an extent that they were often intoxicated and their schoolwork deteriorated. Only $21,7 \%$ $(n=13)$ of the adolescents were addicted to illegal drugs. Furthermore, the study established that peer group pressure and being accepted by their friends were the primary factors that contributed to the problem. However, the fact that more than half of the sample did not live with both their parents and had a poor relationship with their guardians could also be a factor. Dlamini and Makondo (2017) also revealed that drug and substance abuse was prevalent among teenage learners, and the society was encouraging drugs and substances abuse. The escalating rate of drug and substance abuse puts the country at risk of losing generations and underdevelopment owing to the diversion of resources to address among others, basic needs for uneducated and unskilled youth, dependent young adults and increased health care needs among the youth abusing alcohol and drugs. The cost of policing will also be high due to crime resulting from idleness and youth drinking habits. All those compounded will go a long way in frustrating the attainment of the Millennium Development Goals (MDGs) especially the Education for All (E. F. A) Goal, and vision 2022 which envision making Swaziland industrial and mid -level income country. In 2015, the Royal Swaziland Police under the Anti-Drug Abuse Unit reported an alarming statistical level on drug abuse arrest in Eswatini. Therefore, it is against this background that the researcher sought to explore measures that can be employed to curb drug and substance abuse on learners in primary schools in the Hhohho region of Eswatini. 
While it is clear that some research exist in the concept of drug abuse in Eswatini as captured above, the government of Eswatini has implemented the Free Primary Education programme, and this brought to primary schools an overwhelming multitude of enrolments. This brought to schools escalating cases of drug abuse in primary schools which were not previously recorded. While other studies like Dlamini and Makondo (2017) focused on the Shiselweni Region the current study focused on the Hhohho Region. The current study is about measures to be employed to curb the abuse of drugs by primary school learners in the Hhohho region of Eswatini.

\section{Statement of the Problem}

Youth use of harmful legal product constitutes a growing health problem for Eswatini Youth. This is further echoed by Mhlongo (2005) who states that adolescents abuse alcohol to such an extent that they were often intoxicated and their schoolwork deteriorated. Dlamini and Makondo (2017) also revealed that drug and substance abuse was prevalent among teenage learners, and the society was encouraging drugs and substances abuse. The escalating rate of drug and substance abuse puts the country at risk of losing generations and underdevelopment owing to the diversion of resources to address among others, basic needs for uneducated and unskilled youth, dependent young adults and increased health care needs among the youth abusing alcohol and drugs. The cost of policing is also high due to crime resulting from idleness and youth drinking habits. All those compounded will go a long way in frustrating the attainment of the Millennium Development Goals (MDGs) especially the Education for All (E. F. A) Goal, and vision 2022 which envision making Swaziland industrial and mid -level income country. In 2015, the Royal Swaziland Police under the Anti-Drug Abuse Unit reported an alarming statistical level on drug abuse arrest in Eswatini. Therefore, it is against this background that the researcher sought to explore measures that can be employed to curb drug and substance abuse on learners in primary schools in the Hhohho region of Eswatini.

\section{Objectives of the Study}

The main objective of the study is to explore measures that can be employed to curb drug and substance abuse on learners in primary schools in the Hhohho region of Eswatini.

\section{Review of related literature}

Literature for this study is presented following themes that are extracted from the objectives of the study. The themes are as follows: Measures that can be employed to prevent the abuse of drugs, school-based prevention intervention to drug abuse.

\subsection{Measures that could be employed to curb drug abuse among learners}

According to Chakravarthy, Shah and Lotfipour (2013), efforts should be concerted on early identification, awareness and prevention programs, and routine monitoring of adolescent health data. Given the prevailing burden and impact of substance abuse in children and adolescents, it is essential that effective interventions and delivery platforms on enhancing social skills, problem-solving skills, and self-confidence are identified and implemented.

Furthermore, Setlalentoa, Ryke and Strydom (2015) suggest that substance abuse prevention programs should be holistic, multi-level, and multi-sectorial. Bronfenbrenner's socio-ecological framework becomes handy when analyzing interventions as it allows the targeting of interventions to all risk factors at all levels: be it individual, micro, ecosystem and exosystem.

Furthermore, Thwala (2005) has noted that for any intervention to be successful, it should be underpinned by the following set of principles:

- $\quad$ principle 1) Interventions should promote protective factors and seek to lessen risk factors;

- $\quad$ principle 2) prevention programs should be holistic and include all forms of drug abuse;

- $\quad$ principle 3) prevention programs should address the type of drug abuse problem in the local community;

- target families should seek to improve family relationships, including parenting skills, practice in developing, discussing and enforcing family policies on substance abuse, training in drug education and information;

- principle 6) prevention programs for adolescents should increase skills related to studying, communication, peer relationships, self-efficacy, assertiveness and drug resistance;

- $\quad$ principle 7) for maximum effectiveness prevention programs should employ interactive techniques;

- $\quad$ principle 8) prevention programs should intervene and reach appropriate populations in multiple settings such as schools, recreational clubs and religious settings; and

- $\quad$ Principle 9) prevention programs should be used in the long-term with repeated reinforcing sessions over time (Thwala, 2005).

\subsubsection{Individual measures}

At the individual level, literature proposes many strategies for dealing with substance abuse. According to Brooks, Magnusson, Spencer and Morgan (2012) effective strategies at this level target the youth directly and also take 
into account peer influence. Brook observes that combating substance use should involve reversing positive attitudes to drugs and dealing with personality dispositions that predispose them to drug use, and addressing symptoms of mental health problems that may cause and/or exacerbate the abuse of substances. Intervention programs should address poor social skills, e.g. low self-esteem, depression, peer pressure and poor social coping strategies, among others (Larner, 2004). Young people should be trained on how to resist peer pressure as this is the single most important risk factor for the youth. This can be done through promoting youth to youth training programs (Brooks, Magnusson, Spencer and Morgan, 2012).

\subsubsection{Family wide approach}

Meghdadpour, Curtis, Pettifor and MacPhail (2012), found that in South Africa, family supervision is likely to reduce male youths being drunk by $23 \%$ and lowers their chance of using illegal drugs by $38 \%$. Therefore, to combat drug and alcohol abuse emphasis should be placed on strategies that address parental drinking, low parental monitoring, low parental bonding, poor parent-child communication (van Zyl, 2013). Parents have the biggest influence on the learner's behavior. Therefore, its strategies that focus on the improvement of parental abilities that have an effect on the habits of learners regarding drug and substance abuse in the school environment. However, such intervention measures may not be effective or applicable in the case of child-headed households where even the head of the house also needs direction (van Zyl, 2013).

Reports from programs in United Kingdom and United States of America indicate that working closely with families, careers and significant others, improve communication and mobilizes resources in ways that enhance protection of young people (SAMSHA, 2012; Scottish Government, 2011). Importantly, Larner (2004) highlights that therapeutic intervention accounts for approximately $15 \%$ of success regardless of approach and that individual's resourcefulness and chance events accounts for $40 \%$ of the change process combined with expectations and hope for change which is estimated at $15 \%$. The remaining $30 \%$ of the variance influencing outcomes is believed to exist in the relationship between therapists and client. The Family Support Agency (2013, p. 37) acknowledges that some families may need support over an extended period of time and emphasize the value of therapeutic relationships that are emotionally warm, attentive, responsive, sensitive, attuned, consistent and interested.

\subsubsection{Motivational interviewing}

Motivational interviewing (MI) is a goal-directed, client-centered counselling style to help people explore and resolve ambivalence (Barrett, et al. 2012). The approach involves establishing rapport, listening reflectively and asking open-ended questions to explore individual's motivations for change while addressing resistance without confrontation and encouraging self-efficacy (Carr, 2010). In addition to this, Jensen, et al. (2011) observe that interventions may be most effective in the early stages of substance use through generating awareness of the discrepancy between current behavior and desired behavior.

\subsubsection{Media intervention}

According to Stoolmiller, Wills, McClure, Tanski, and Worth (2012), the media can play an influential role in changing society. In the campaign of reducing substance abuse in adolescent, media need to be involved from beginning till the end of the campaign. Local media could be involved as partners in this campaign. Media can do marketing by showing positive influence for prevention of drug abuse. Stoolmiller, Wills, McClure, Tanski, and Worth (2012) further state that the media need to telecast talk shows, announcements related to the programme, conferences, story making, newspaper article coverage and commercials to prohibit substance use among youths.

\subsubsection{School-based intervention prevention}

A study by Gottfredson (2013) suggest that targeting middle school aged children and designing programs that can be delivered primarily by peer leaders will increase the effectiveness of school-based substance use prevention programs. The study further targeting higher risk youth may yield stronger effects than targeting the general population.

Another study by Rohrbach (2014) concluded that program implementation was highly variable, suggesting that widespread teacher use of psychosocial based programs cannot be taken for granted. Strategies for increasing implementation and maintenance need to be developed.

Hensen (2003) suggest that comprehensive and social influence programs are found to be most successful in preventing the onset of substance use.

\section{Theoretical Framework}

The study was guided by the Bronfenbrenner's ecological systems theory. The ecological systems theory maintains that it is vital to note that an environment and its immediate settings actively shape the outcome of an individual's life. People do not live in isolation but rather within multifaceted structures that contain their immediate settings, social networks and traditional communities established in a wider social structure (Adams, Dominelli \& Payne, 2009). Bronfenbrenner (1989) argues that people are both producers and products of their development. This theory indicates clearly how a human infant is naturally prone to act on his or her surroundings. He also argues that people have distinct features that invite or reject responses from the environment. In so doing they foster or 
discourage development (Bronfenbrenner, 1989). One of the main assumptions of the ecological theory is that an individual and his background both have an impact on each other (Green, 2011).

Bronfenbrenner's ecological systems theory divides the environment into five different levels. The microsystem refers to the immediate environment, for example sex, age health etc. The mesosystem refers to interconnections between the microsystems; interactions between the family and teachers; and relationship between the child's peers and the family. The exosystem involves the link between a social setting in which the individual does not have an active role and the individual's immediate context. The macrosystem describes the culture in which individuals live. Chronosystem is the patterning of environmental events and transition over the life course, as well as socio historical circumstances. The theory befits the study since it stressed the importance of studying a child in the context of multiple environments (also known as ecological system) in an attempt to understand his development. In the case of this study, the researchers sought to explore measures that can be employed to curb drug abuse by primary school learners in the Hhohho region of Eswatini. This theory futher indicates the significant of stakeholders working in a synegistic form towards a targeted goal. In this case, schools need to adopt strategies that help learners recognize and deal with social influences to use drugs from peers and the media to control the drugs and substance abuse problem. This theory is also relevant to this study in that it provides the framework to help understand how social influences play a pivotal role in the abuse of drugs among young people.

\section{Presentation of findings}

For the systematic presentation of data, a schedule of themes which were identified in the study is presented first, and this schedule is then used as a guide to data presentation and analysis thereof.

\subsection{Awareness campaigns}

It was agreed among the teachers that the school in partnership with the relevant departments in government should come up with some robust awareness campaign to encourage learners to avoid the use of drugs. One of the teachers had this to say:

Schools can only rely on the lessons they provide during assembly. Ask some other departments like police and health have sessions to those who raise awareness accessible to drugs. Teach about the dangers of drugs (Participant \# 8: 45 year old teacher).

This was also supported by learners in one of the focus group discussions when they said the following:

If the police come and address us, it improve our knowledge about the dangers of these drugs and also it can scare those who are selling to stop. Everyone knows, Learners are afraid of the police (Learner \# 20, 15 year old Boy, FGDB).

I think at school our teachers can do more in trying to educate us on the real dangers of drugs like dagga and alcohol, sometime as learners no one gives us this information so we do it without knowledge (Learner \# 11:14 year old Boy, FGDA).

\subsection{Counselling programmes.}

A number of learners supported the use of counseling as a preventative measure and in this regard one learner said this during the focus group discussion;

If our school can be like other schools with guidance and counselling teachers it can help us cope with some of our problems so that we avoid thinking drugs or playing with friends who use them and end up giving us bad advice (Learner \# 20, 15 year old Boy, FGDB).

This was fully supported by teachers who participated in individual interviews. Accordingly, two teachers said that:

The purpose of guidance of counselling is to give learners direction and help the make the best decision that promote the learning goals of the students. Unfortunately in some of our rural schools do not have the personnel and resources to have such an office (Participant \#4: 48 year old, Teacher).

Guidance and counseling does help a lot and often some learners sucked in by the drug cancer find he;p and build their lives thereof (Participant \# 8: 45 year old teacher).

\subsection{Formation of clubs on anti-drugs.}

The formation of clubs was supported by some teachers as provided by one of them who said that:

Clubs are an essential part of resolving such social problems through the engagement and dialogue among affected individuals. Such groups can actually run smaller campaigns in the school sensitizing all learners about the dangers of drug abuse among learners (Participant\# 9: 32 year old teacher).

Another teacher echoed this by saying: 
Clubs are very practical ways of dealing with the problem because learners get to express their actions against drug abuse in a social environment. Clubs also keep the learners from having too much excess time and more time after formal lessons are done (Participant\#3: 49 year Teacher).

\subsection{Job creation strategy.}

It was suggested by one of the teachers that the community can embark on a number of self-sustainable projects to provide jobs as well as occupy the time of teenagers. The teacher had this say:

It's important that communities around seek for funding and laugh different projects that will be aimed at employing teenagers from local schools. This has an effect of benefiting the learners economically and taking them off the way of harm which usually occurs when they are idle (Participant\#3, 49 year old, teacher).

Learners were in support of the creation of some work activities as given by one of them who had this to say:

It possible the school can study some projects for us like gardening, chicken rearing so that we get the cash from working (Learner \# 20, 15 year old Boy, FGDB).

\subsection{Spot check bags.}

It was suggested by the teachers that the school should be stricter and carry out spot checks of bags randomly. In this regard one teachers said that

The bags of learners need to be searched randomly; this will keep learners on their toes and can reduce the amount of drugs in the school. Without spot checks it will be difficult to stop learners bring drugs under control (Participant \# 1: 40 year old teacher).

Another participant said that:

Spot checks are a great because they expose a lot, during such checks cell-phones and drugs and other weapons can be impounded (Participant \# 10: 39 year old Teacher).

\subsection{Media counter campaigns.}

It was the view of the majority of the teachers that the same media used to prolifically sell and peddle drug messages can also be used to transmit messages of hope and positivity regarding the dangers of drug abuse. In this regard one participant said that:

For every alcohol advert out there, the Ministry of Health and concerned NGOs must push and flight as counter advertisement which indicates all the bad effects of drug abuse. Such adverts must show the vile consequences of drug abuse so the learners understand what happens in the real world (Participant \# 8, 45 year old Teacher).

Another teacher supported this by saying:

The social media and television can be used to show the counter the communications promoting the use of drugs. Young unsuspecting learners needs the full information and in my opinion concerned organizations and departments are not making enough noise using these tools to ensure teenagers are truly informed about the bad and real effect of drug and substance abuse (Participant \# 9: 32 year old Teacher).

\section{Discussion of Findings}

In this section the findings are discussed. The discussion of findings reviews the findings of the study in comparison to the findings made by other researchers as recorded in the second chapter of this study. The discussion is also guided by the research objectives which are recited as follows: to identify measures that could be employed to curb drug abuse among learners in public primary schools in the Hhohho region of Eswatini, to identify school-based prevention interventions to drug abuse.

With reference to the measures that could be employed to curb drug abuse among learners, the findings of the study included media countering. This is a strategy whereby the media is used as a tool to indicate that drug abuse is not the best option for learners. This would educate learners significantly and improve decision making. Stoolmiller, Wills, McClure, Tanski, and Worth (2012), argue that the media can play an influential role in changing society. In the campaign of reducing substance abuse in adolescent, media needs to involve from beginning till the end of the campaign. Local media could be involved as partners in this campaign.

It was also revealed that the responsible departments of government such as the Ministry of health could ensure that emphatic awareness campaigns are made to educate learners about the dangers of drug abuse. Such findings are in line with Jensen, et al. (2011) who posits that interventions may be most effective in the early stages of substance use through generating awareness of the discrepancy between current behavior and desired life goals.

\section{Conclusions}

The main purpose of the study was to explore the measures to be employed to curb the abuse of drugs by primary 
school learners in the Hhohho region of Eswatini. The objectives of the study were 1) to establish measures to be employed to curb the abuse of drugs by primary school learners in the Hhohho region of Eswatini; .2) to explore school-based prevention intervention in the abuse of drugs by primary school learners in the Hhohho region of Eswatini.

This study adopted a qualitative research approach. A case study design was used for the study and involved one school only. The total number of participants was thirty (30). These participants comprised of ten (10) teachers and twenty (20) learners. Participants were selected using purposive sampling. Data collection instruments used included focus group discussions for the learners and individual face to face interviews for the teachers. The study used thematic analysis to draw meaning out of the collected data.

The study concludes that that family challenges were key stressors driving learners into drug and substance abuse. The study also concludes that loneliness and boredom was a key factor leading to learners engaging into drug abuse. It was also conclusive that the pressure on learners to perform well was also responsible for the rise in drug and substance abuse by learners. Peer pressure was concluded to be one of the most influential causes of learners abusing drugs. The study also concludes that media in general and social media in particular was a key cause of learners getting into the abuse of drugs.

\section{Recommendations}

In this section the recommendations viewed as important to mitigate the problems discovered in the study are provided:

- Ministry of Health could ensure that emphatic awareness campaigns are made to educate learners about the dangers of drug abuse.

- The government in conjunction with civic groups may launch a social media campaign targeting young people. The campaign can discourage the use of drugs and illegal substances. This campaign may engage high profile role models to ensure maximum impact of the message.

- Schools may discourage learners from use of drug and substance abuse through extensive peer education through schools departments such guidance and counselling and life skills education.

- $\quad$ The community leaders may encourage residents to be responsible community members by discouraging employment of learners in dagga farming and selling. Community leaders may also be advocates of good parenting among its members and this may include the dangers of using drugs in the full view of learners and children below the age of majority.

- The justice department may consider stiffer penalties for illegal use of drugs so that offenders are used as deterrent examples.

- Schools may consider a composite number of strategies to reduce performance pressure on leaners including guidance and counselling, positive discipline, and motivation of learners.

\section{References}

Addams, R., Dominelli, L. \& Payne, M., (2009). Critical Practice in Social Work, (2nd Ed.). Australia, Amazon: Palgrave Macmillan Inc.

Barrett, E., Sussman, S. Smith, C. Roribach, L.A. \& Sparijt-Metz, D. (2012). Motivational Interviewing for Adolescent Substance Use: A review of literature. Addictive Behavior, 37,

Botvin, G. J., (1970). Botvin Life Skills Training. Retrieved from weilcornell.org/gjbotvin.

Braun, V. \& Clarke, V. (2013). Successful qualitative research: A practical guide for beginners. London: Sage.

Bronfenbrenner, U., (1979). The ecology of human development. United States of America: Harvard College.

Bronfenbrenner, U. (2013). The Ecology of human development. Retrieved from https://www.psychologynoteshq.com

Chakravarthy B, Shah S, Lotfipour S. (2013). Adolescent drug abuse-awareness \& prevention. Indian J Med Res 137:1021.

Dlamini P. \& Makondo, D. (2017). The prevalence of drug and substance abuse among school going teenagers in the Shiselweni Region of Swaziland. International Journal of Innovation and Applied Studiem 20(2), 652660.

Farlex, B. (2013). Drug abuse. Retrieved from http://medical dictionary. Faria, E. A., Queiros P. S., Medeiros, M., Rosso, C., \& Souza, M. (2015). Perceptions of adolescent students about drugs. Rev. Bras. Enferm. 68(4), 457-63. DOI: http://dx.doi.org/10.1590/0034-7167.2015680320i.

Jensen, C. D., Cushing, C. C. Aylward, B.S. Craig, J. T. Sorell, D. M. \& Steele, R.G. (2011). Effectiveness of Motivational Interviewing Interventions for Adolescent Substance Use Behavior Change: A Meta-Analytic Review, Journal of Consulting and Clinical Psychology, 79 (4), 433-444

Kavutha, J. M. 2015). Influence of drug use on academic performance among secondary school students in Matinyani District, Kenya. International Journal of Scientific and Research Publications, 5, (11), 2250-3153. Retrieved from www.ijsrp.org. 
Meghdadpour, S., Curtis, S., Pettifor, A. \& MacPhail, C. (2012). Factors associated with substance use among orphaned and nonorphaned youth in South Africa. Journal of Adolescence, 35(5)1329-1340.

Mhlongo, T. (2005). Drug Abuse in Adolescents in Swaziland. Unpublished dissertation. University of South Africa.

Mudavanhu, N. \& Schenck, R. (2014). Substance Abuse amongst the Youth in Grabouw Western Cape: Voices from the Community. Social Work/Maatskaplike Werk, 3(4), 50. Retrieved from http://socialwork.journals.ac.za/pub.

Ongwae, M. N. (2016). A study of the causes and effects of drug and substance abuse among students in selected secondary schools in Starehe Sub Country. Nairobi Country.

Reddy, S.P., James, S., \& Sewpaul R. (2010). Umthente Uhlaba Usamila - The South African Youth Risk Behavior Survey 2008. Cape Town: South African Medical Research Council.

Setlalentoa, M., Elma, R. \& Herman, S. (2015). Intervention strategies used to address alcohol abuse in the North West province, South Africa Social work 51.

Stoolmiller, M., Wills, T.A., McClure, A.C., Tanski, S.E., \& Worth, K.A. (2012). Comparing media and family predictors of alcohol use: a cohort study of US adolescents. BMJ Open, 2, 543.

Thwala, S., (2005). Challenges encountered by teachers in managing inclusive classrooms in Swaziland. Swaziland, Kwaluseni: University of Swaziland,

Van Zyl A. E. (2013). Drug use amongst South African Youths: Reasons and Solutions. Mediterranean Journal of Social Sciences, 4 (14).

Warner, R., (2013). Applied statistics from bivariate through multivariate techniques, 2nd ed. Retrieved from psychet.apa.org 2013>37548-000.

Yin, R. K. (2014). Case study research: Design and methods (5th Ed.). Thousand Oaks: Sag 